\title{
About Effect of Hydroelectric Construction on Some Features of Fish Biology
}

\author{
Inga Vladimirovna Matrosova ${ }^{1 *}$, Galina Georgievna Kalinina ${ }^{1}$ \\ ${ }^{1}$ Far Eastern State Technical Fisheries University, Engineering Disciplines Department, 52 B \\ Lugovaya Str., Vladivostok 690087, Russia
}

\begin{abstract}
Restructures in the communities of hydrobionts take place for the rivers with abrupt changes in hydrography and hydrological regime, as a result of flow regulation. They require long-term monitoring to develop preventive measures to avoid negative consequences and to restore the river ecosystem. Some biological characteristics of the broad whitefish (Coregonus nasus) have been studied during spawning migration in the upper reaches of the Yenisei River. The limiting values of the fish length were higher in 2016, and the average - in 2013. In 2013, the sampling frame consisted of fish of 51-55 cm in size, in 2014 and 2016. - 41-45 cm. In 2013, most of the fish in the catches were aged from $6+$ to $11+$ years, in $2014-$ from $8+$ to $10+$ years, in $2016-$ from $8+$ to $11+$ years. The gender ratio was close to $1: 1$; most of the individuals had gonads at maturity stage III.
\end{abstract}

\section{Introduction}

As a result of hydroelectric construction, a number of water reservoirs have been appeared in the Yenisei River basin. With the commissioning of the Krasnoyarsk hydroelectric power station in the Yenisei River, a change in the hydrological, hydrochemical and hydrobiological regimes took place. The consequences of regulation can be traced according to some indicators at a considerable distance from the alignment of the hydroelectric complex [1]. Any rearrangements in communities of hydrobionts require in-depth study and long-term monitoring to obtain statistical information on the river ecosystem [1-13].

In the lake-river system of the Upper Yenisei (Tyva Republic), one of the representatives of the whitefish was found - the broad whitefish (Coregonus nasus, Pallas, 1776) [14]. Whitefish are valuable commercial fish that provide a significant share of fish products in freshwater reservoirs of Siberia. The study of the biological features of whitefish in the large spawning rivers of Siberia - the Ob, Yenisei, Lena, and Kolyma - is used to calculate the damage to fisheries, to develop the measures for the protection of fish resources, and to plan fishing.

A goal of research was to study and to supplement some biological characteristics of the broad whitefish of the Yenisei River. To achieve this goal, it was necessary to study the size, weight, and age composition; to characterize the gender ratio and the degree of maturity of the gonads.

* Corresponding author: Matrosova.IV@dgtru.ru 


\section{Research materials and methods}

The data for the research were provided to the authors by the employees of the department of Processing of agricultural products, fisheries, food security of the Ministry of Agriculture and Food of the Republic of Tyva (Kyzyl) (Table 1). Primary data were collected in 2013, 2014, and 2016 during the spawning migration of broad whitefish in the upper reaches of the Yenisei. A river seine was used as a fishing gear. Biological analysis was performed according to the generally accepted method [14].

Table 1. The basic data.

\begin{tabular}{|c|c|}
\hline Year (month) & $\begin{array}{c}\text { The number of fish taken for biological } \\
\text { analysis, ind. }\end{array}$ \\
\hline $2013(20.08 .-28.08)$ & 100 \\
\hline $2014(18.08 .-25.08)$ & 100 \\
\hline $2016(16.08 .-25.08)$ & 81 \\
\hline Total & 281 \\
\hline
\end{tabular}

\section{Research results}

Within the framework of monitoring the state of the broad whitefish, its main biological characteristics were studied.

\subsection{Size composition}

According to the data published in 1980-1987, in the commercial catches, fish of 37-45 cm in length were present $[14,15]$. When we studied, along with this size group, there were also large individuals (more than $45 \mathrm{~cm}$ in length).

According to our data, the size composition of the broad whithefish in 2013 was represented by individuals from 27 to $60 \mathrm{~cm}$ in length (Table 2). Most of the fish in the commercial catches had a length of $51-55 \mathrm{~cm}(52.2 \%)$, in the range of $46-50 \mathrm{~cm}-29.8 \%$ (Table 2).

The broad whitefish of 31 to $60 \mathrm{~cm}$ in length was encountered in 2014 (Table 2). The most of the individuals had a length of 41 to $50 \mathrm{~cm}$. The smallest number of fish was in the range of 31-35 and $56-60 \mathrm{~cm}$.

In 2016, the size of the broad whitefish varied from 36 to $75 \mathrm{~cm}$ (Table 2). The modal group included fish from 41 to $50 \mathrm{~cm}$. Most of the fish were $41-45 \mathrm{~cm}$ long.

The limiting values of the broad whitefish length were higher in 2016, and the average in 2013. In 2013, the sampling frame consisted of fish of 51-55 cm in size, and in 2014 and 2016 , it was $-41-45 \mathrm{~cm}$.

Table 2. Broad whitefish length in 2013, 2014, and 2016.

\begin{tabular}{|c|c|c|c|c|}
\hline Year & $\mathbf{n}$, ind. & $\mathbf{X}_{\mathbf{m i n}}, \mathbf{c m}$ & $\mathbf{X}_{\mathbf{m a x}}, \mathbf{c m}$ & $\bar{X}_{ \pm} \mathbf{m}_{\mathbf{x}}, \mathbf{c m}$ \\
\hline 2013 & 100 & 27 & 60 & $48,9 \pm 1,01$ \\
\hline
\end{tabular}




\begin{tabular}{|l|l|l|l|l|}
\hline 2014 & 100 & 31 & 60 & $45,1 \pm 0,58$ \\
\hline 2016 & 81 & 36 & 75 & $47,3 \pm 0,78$ \\
\hline
\end{tabular}

\subsection{Weight composition}

The weight composition reflects the nature of fish nutrition and the food supply of the water reservoir. By the weight of the fish, one can speak of the presence of food items or their absence. According to the data published in 1980-1987 the commercial catches included fish weighing from 1 to $2.2 \mathrm{~kg}[14,16,17]$.

When we studied, the weight of individuals varied from 380 to $3950 \mathrm{~g}$ (Table 3). Most individuals had a mass in 2013 from 1240 to $1700 \mathrm{~g}$, in 2016 - from 1540 to $2100 \mathrm{~g}$.

Table 3. Weight of broad whitefish in 2013, 2014, and 2016.

\begin{tabular}{|c|c|c|c|c|}
\hline Year & n, ind. & $\mathbf{X}_{\text {min }}, \mathbf{g}$ & $\mathbf{X}_{\text {max }}, \mathbf{g}$ & $\bar{X}_{ \pm} \mathbf{m}_{\mathbf{x}}, \mathbf{g}$ \\
\hline 2013 & 100 & 420 & 3450 & $1822 \pm 190,2$ \\
\hline 2014 & 100 & 380 & 3120 & $1523 \pm 139,4$ \\
\hline 2016 & 81 & 450 & 3950 & $1976 \pm 129,4$ \\
\hline
\end{tabular}

\subsection{Age composition}

For the natural replenishment of a fish population in a water reservoir, knowledge of the average age of the population is of direct importance for its reproduction.

Broad whitefish is a long-lived fish. According to the data published in 1980-1987 in the commercial catches there were individuals aged from $1+$ to $22+$ years [14-18]. Most were between the ages of $3+$ and $6+$ years. Until 1980, the most common fish in catches were at the age of $4+-6+$ and $13+, 14$ years [19-27].

According to our data, in 2013, the minimum age of fish was $3+$ years, and the maximum age was $15+$ years. The modal class consisted of individuals of $10+$ years. Most of the fish were from $6+$ to $11+$ years old.

In 2014, the minimum age of fish was $4+$ years, and the maximum age was $15+$ years. The modal class consisted of individuals $9+$ years. Most of the fish were aged from $8+$ to $10+$ years.

In 2016, the smallest age was 4+ years, the largest $-17+$ yeras. Most of the fish were aged of $8+-11+$ years. Age groups from $5+$ to $11+$ years accounted for $80 \%$ of the catch.

\subsection{Gender ratio}

The gender ratio is an adaptive property of fish and is aimed at ensuring the enhanced reproduction. As a rule, in a small amount, broad whitefish matures at the age of $4+-5+$ years, but the mass maturity of this fish species in the rivers of Siberia occurs at $7+-9+$ and even at $10+-12+$ years. The maturation of each generation lasts $3-4$ years [14-18]. 
In 2013, the gender ratio of broad whitefish was practically equal: $52 \%$ of females and $48 \%$ of males. The sampling frame consisted of individuals with gonads at maturity stages III and IV (Fig. 1). Females matured faster than males.

In 2014 and 2016, the proportion of females was $52.3 \%$, and the proportion of males $47.7 \%$, which corresponds to a sex ratio of $1: 1$.

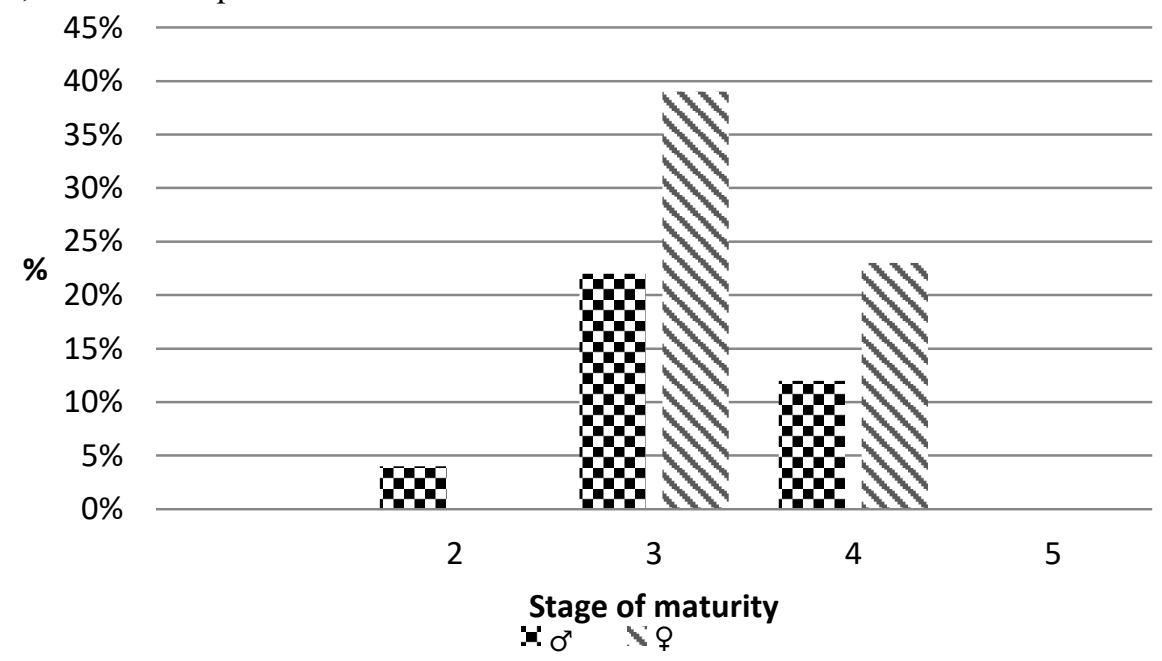

Fig. 1. Maturity stages of broad whitefish gonads in 2013

In the catches of 2014 and 2016 the most of the individuals had gonads at the III stage of maturity, and the majority were males - about $60 \%$, while the females were only $23 \%$.

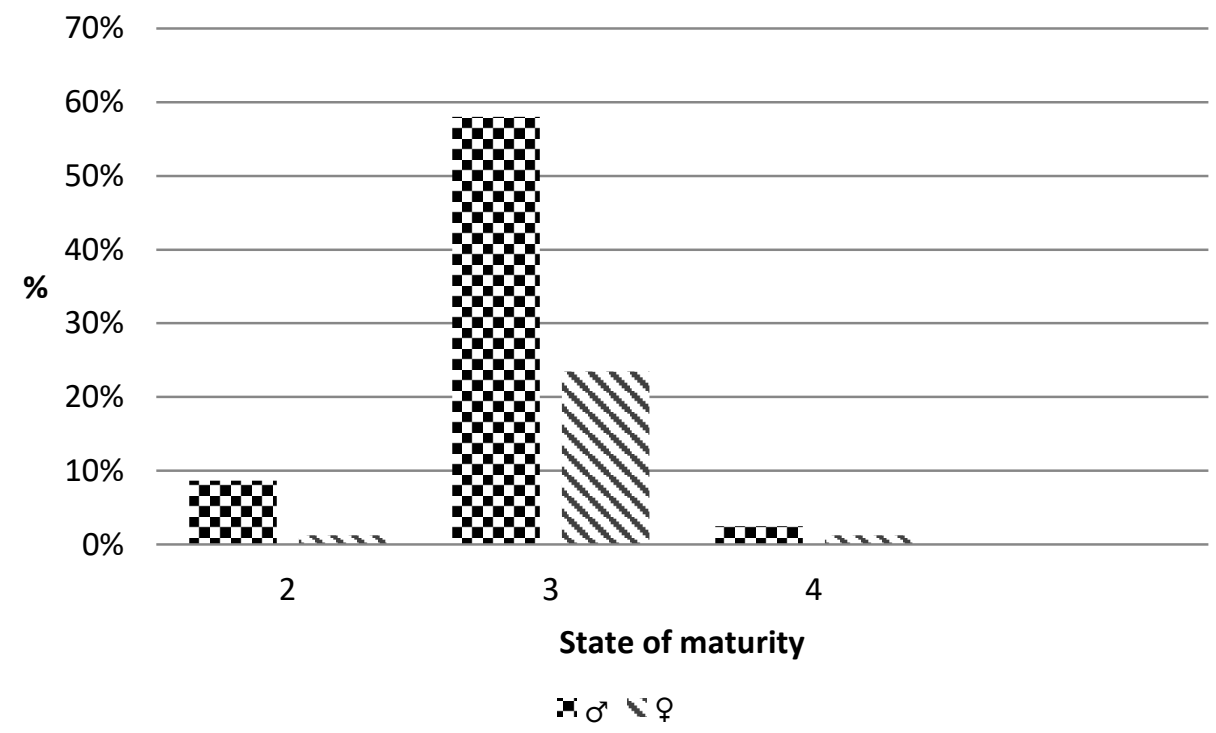

Fig. 2. Maturity stages of broad whitefish gonads in 2014 and 2016

Thus, in the years of our study, the gender ratio was 1: 1; most of the individuals had gonads at stage III of gonad maturity. 


\section{Conclusions}

As a result of the research carried out, the following conclusions can be made.

In 2013 and 2016 the size of the broad whitefish in the Yenisei River varied from 27 to $75 \mathrm{~cm}$, the average length was greater in $2013-48.9 \pm 1.01 \mathrm{~cm}$. The weight of the broad whitefish varied from 380 to $3950 \mathrm{~g}$, the average weight was greater in $2016-1976 \pm 129.4$ g. During the years of the study, no differences in the values of the length and weight of females and males were found.

The catches included individuals aged from $3+$ to $17+$ years; in 2013, the sampling frame consisted of fish aged from 6+ to 11+ years, in 2014 - from 8+ to 10+ years, in 2016 - from $8+$ to $11+$ years. Individuals of the same age had a significant variation in body length and weight. A number of authors associate the uneven growth of broad whitefish with a low food supply for zoobenthos in rivers as compared to lakes. According to Andriyanova A.V. after the regulation of the Yenisei, the quantitative characteristics of zoobenthos increased significantly, especially in the area from the dam to the mouth of the Angara [1]. This is most likely not the only reason for the uneven growth of the broad whitefish.

In the years of our study, the gender composition in the catches was practically equal. In 2013, the sampling frame (96\%) consisted of individuals with gonads at stages III and IV of maturity, in 2014 and 2016, fish with gonads at maturity stage III predominated (81\%).

According to literary data, in the Yenisei the broad whitefish becomes sexually mature in the seventh-eighth year of life, with a length of $43-48 \mathrm{~cm}$ and a weight of $1.3-2.1 \mathrm{~kg}$. The time of puberty in the broad whitefish depends on the living conditions and stretches for 3-4 years [20]. A significant part of the catches in 2013, 2014, and 2016 were young producers, that is, individuals spawning for the first time or in the second year after the onset of puberty.

Our data are consistent with the literature data that earlier in commercial catches the broad whitefish was found at the age of up to 18-22 years, now individuals older than 10-12 years are rare [19-22]. The reason is probably that in most fishing areas of Siberia, broad whitefish is harvested at the age of 4-7 years, thus reducing the reproductive potential of the populations of this species. On the whole, the main biological characteristics of the broad whitefish are consistent with the literature data.

The information we have obtained on some biological parameters of the broad whitefish in the Yenisei River supplements the information about it in the framework of monitoring the regulated river ecosystem.

\section{References}

1. A.V. Andriyanova, Tomsk State University Bulletin, 1 (21), 74-88 (2013)

2. EPRI (Electric Power Research Institute) Environmental Effects of Hydrokinetic Turbines on Fish: Desktop and Laboratory Flume Studies Bickford, 220 (2012)

3. S. A. and J. R. Skalski. North American Journal of Fisheries Management, 20, 53-68 (2000)

4. T. Castro-Santos, A. J. Haro and S. Walk A passive integrated transponder (PIT) tagging system for monitoring fishways. Fisheries Research 28, 253-261 (1996)

5. T. Castro-Santos and A. J. Haro. Canadian Journal of Fisheries and Aquatic Sciences 60, 986-996 (2003)

6. T. Castro-Santos, The Journal of Experimental Biology, 208 (3), 421-432 (2005)

7. EPRI (Electric Power Research Institute). Evaluation of Fish Injury and Mortality Associated with Hydrokinetic Turbines. Palo Alto, CA. 1024569. November 2011 (2011)

8. J. W. Ferguson, R. F. Absolon, T. J. Carlson and B. P. Sandford. Evidence of delayed mortality on juvenile Pacific salmon passing throughturbines at Columbia River Dams. Transactions of the American Fisheries Society, 135(1), 139-150 (2006) 
9. A. Haro, T. Castro-Santos, J. Noreika and M. Odeh. Canadian Journal of Fisheries and Aquatic Sciences, 61(9), 1590-1601 (2004)

10. J. E. Harris and J. E. Hightowe. Marine and Coastal Fisheries, 4, 262-283 (2012)

11. E. L. Kaplan and P. Meier. Journal of the American Statistical Association, 53, 457-481 (1958)

12. S. D. McCormick, L. P. Hansen, T. P. Quinn and R. L. Saunders Canadian Journal of Fisheries and Aquatic Sciences, 55, 77-92 (1998)

13. R. L. McLaughlin, E. R. B. Smyth, T. Castro-Santos, M. L. Jones, M. A. Koops, T. C. Pratt and L.-A. Vélez-Espino Fish and Fisheries: DOI: 10.1111/faf.12003 (2012)

14. V.A. Ignatiev, Morphology and ecology of broad witefish: Abstract. Dis. Cand. biol. sciences, 20 (1972)

15. A.I. Andrienko, Kuklin A.A. Proceedings of research papers of GosNIORH, 296, 93-99 (1989)

16. V.D. Bogdanov, Current state of whitefish populations in the Ob River // Biology and biotechnics of whitefish breeding, 11-13 (1994)

17. A.A. Vyshegorodtsev, Fish of Yenisei: directory, 237 (2000)

18. V.I. Golovko, Biological and fishery research of the Bolshoi Kheta river basin. Water reservoirs of Siberia and prospects for their fishery use, 24-25 (1973)

19. V.A. Zadelenov, Enikeeva I.G., Shadrin E.N., Shchur L.A. Siberian ecological journal. 13 (4), 495-502 (2006)

20. V.A. Krasikova, Sesiagin S.M. Biology and fishery of the broad whitefish Coregonus nasus (Pallas) of the Pyasina River // Fish and forage resources of the river basins and water reservoirs of Eastern Siberia, 231-245 (1967)

21. A.V. Podlesny, VNIORH Bulletin, 44, 97-178 (1958)

22. P.A. Popov, Siberian Branch of the USSR Academy of Sciences Bulletin. Series: Biol. science (1), 62-66 (1986)

23. P.A. Popov, Influence of the anthropogenic factor on water ecosystems of the right-bank tributaries of the Lower Yenisei // Ecology and Practice, 102-104 (1989)

24. P.A. Popov, Fish of Siberia: distribution, ecology, catch: monograph, 526 (2007).

25. Yu.S Reshetnikov, Ichthyology issues, 51 (4), 502-525 (2011)

26. E.A. Borovikova, Advances in modern biology, 129 (1), 58-66 (2009)

27. N.N. Sushchik, Gladyshev M.I., Moskvichova A.V. et al. Comparative Biochemistry and Physiology. Part B, 134, 111-122 (2003) 